\title{
Endoscopic Resection and Radiofrequency Ablation for Early Esophageal Neoplasia
}

\author{
Kamar Belghazi Jacques Bergman Roos E. Pouw \\ Department of Gastroenterology and Hepatology, Academic Medical Center, Amsterdam, The Netherlands
}

\begin{abstract}
Key Words
Barrett's neoplasia - Early esophageal neoplasia - Early cancer · Endoscopic resection · Radiofrequency ablation
\end{abstract}

\begin{abstract}
Background: In the last few decades, endoscopic treatment of early neoplastic lesions in the esophagus has established itself as a valid and less invasive alternative to surgical resection. Endoscopic resection (ER) is the cornerstone of endoscopic therapy. Next to the curative potential of ER, by removing neoplastic lesions, ER may also serve as a diagnostic tool. The relatively large tissue specimens obtained with ER enable accurate histological staging of a lesion, allowing for optimal decision-making for further patient management. ER was pioneered in Japan, mainly for the resection of gastric lesions and squamous esophageal neoplasia, and also Western countries have been increasingly implementing ER in the treatment of early gastroesophageal neoplasia, mostly associated with Barrett's esophagus (BE). In BE, however, there is still a risk of metachronous lesions in the remainder of the Barrett's after focal ER. Additional treatment of all Barrett's mucosa is therefore advised. Currently, the most effective method for this is by using radiofrequency ablation (RFA). This review will provide an overview of indications for ER and RFA. Key Messages and Conclusions: Endoscopic management of early esophageal neoplasia is a safe and valid alter-
\end{abstract}

native to surgery and is nowadays the treatment of choice. ER is the mainstay of endoscopic management of early esophageal neoplasia since it allows for removal of neoplastic lesions and provides a large tissue specimen for histological evaluation. In case of early neoplasia in BE, focal ER should be complemented by eradication of the remaining Barrett's mucosa. RFA has proven to be a safe and effective modality to achieve complete eradication of Barrett's mucosa.

(c) 2016 The Author(s)

Published by S. Karger AG, Basel

\section{Introduction}

The last decades endoscopic treatment has been proven a safe and effective alternative to surgery for the treatment of early neoplasia of the upper gastrointestinal tract [1-5]. Endoscopic resection (ER) is the cornerstone of endoscopic management, since it not only has a curative potential by removing neoplastic lesions, but also serves as an excellent diagnostic aid [6] (fig. 1). ER was pioneered in Japan, mainly to resect early gastric cancers and early squamous lesions in the esophagus [5, 7-9]. Also, in Western countries, endoscopic treatment has gained acceptance and is currently in most guidelines advised as treatment of choice for early esophageal neoplasia. In the West, the majority of early neoplastic lesions are associated with Barrett's esophagus (BE) [1-4]. In contrast to

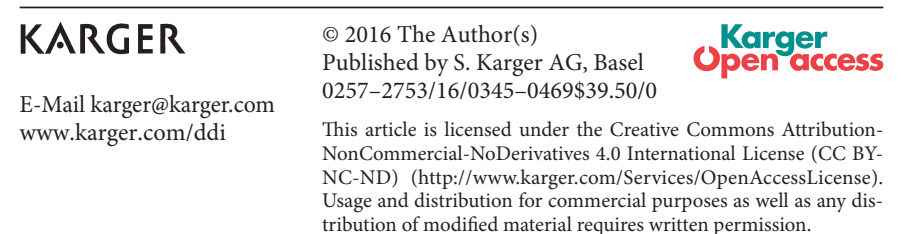

Roos E. Pouw, MD, $\mathrm{PhD}$

Department of Gastroenterology and Hepatology

Academic Medical Center

Meibergdreef 9, NL-1105 AZ Amsterdam (The Netherlands)

E-Mail r.e.pouw@amc.nl 

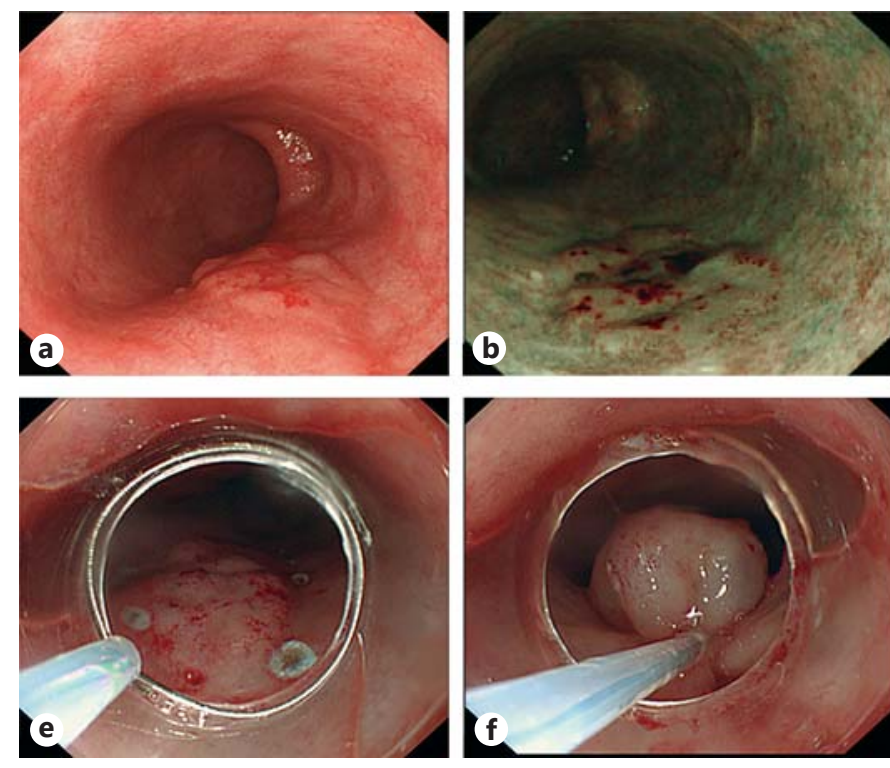

Fig. 1. En bloc ER using the ER cap technique. a A type 0-IIa lesion with a diameter of $15-20 \mathrm{~mm}$ arising in a BE. b, c The margins of the lesion are delineated with chromoendoscopy using indigo carmine (c) and narrow band imaging (b). d Coagulation markings are placed around the lateral margins of the lesion. e After submucosal lifting, an electrocautery snare is prelooped in a distal rim in

surgical resection, which also allows for dissection of local lymph nodes, ER is limited to local removal of a lesion, while leaving the esophageal integrity intact. Curative endoscopic treatment can therefore be reached only in patients with a minimal risk of lymph node metastases. This implies that optimal selection of patients for ER is of the utmost importance. Lesions limited to the mucosa (i.e., T1m1-m3) are associated with a minimal risk of lymphatic involvement and may be treated endoscopically [10-13]. Lesions infiltrating deep into the submucosa $(>\mathrm{T} 1 \mathrm{sm} 1,>500 \mu \mathrm{m})$, poorly or undifferentiated cancer, or the presence of lymphatic/vascular invasion are considered risk factors for lymph node metastasis and exclude a patient from curative endoscopic treatment $[12,13]$. Next to detailed endoscopic inspection of a lesion, the optimal staging tool is a diagnostic ER that provides a relatively large tissue specimen for accurate histological evaluation of these risk factors, on which further patient management can be based [6].

In the case of early neoplasia arising in BE, ER of macroscopic lesions only removes a focal area from the Barrett's segment. The risk of metachronous lesions in the remainder of the Barrett's during follow-up remains [14]. To prevent development of such metachronous lesions, ER can be combined with ablative therapy of all remain-

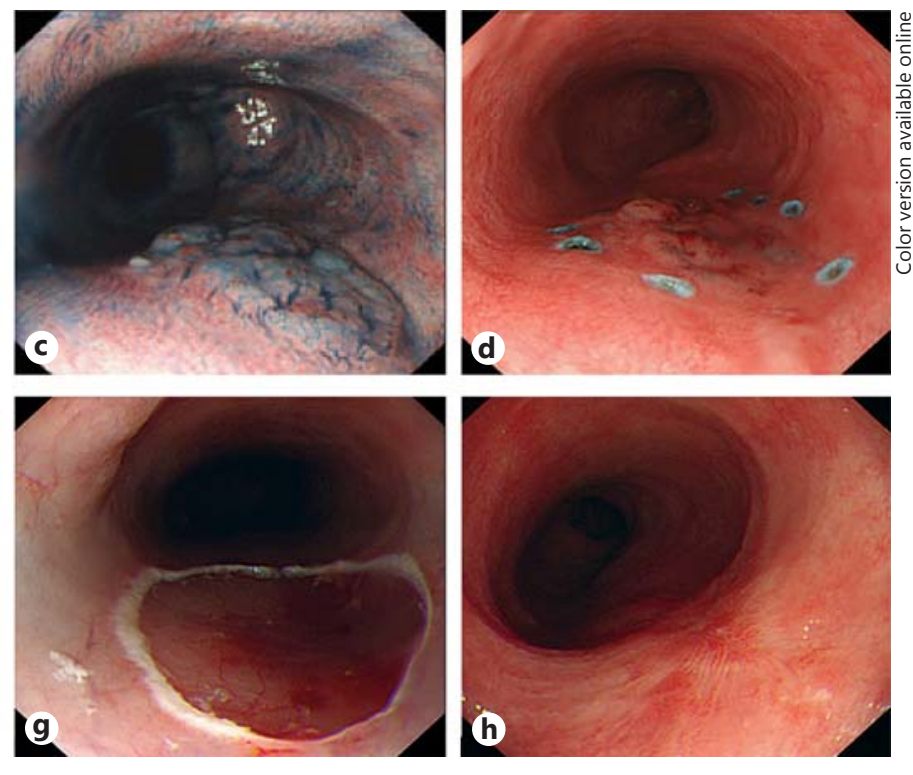

the ER-cap, and the lesion is targeted. $\mathbf{f}$ The lesion is sucked into the cap and by closing the snare a pseudo-polyp is created. $\mathbf{g}$ The resection was endoscopically radical, since all markings have been resected. $\mathbf{h}$ Eight weeks after the ER, the resection wound has healed with scarring. Published with permission of www.barrett. nl.

ing Barrett's. Ablative tools used for this purpose are for example photodynamic therapy (PDT) or argon plasma coagulation (APC) [15-19]. PDT and APC, however, have significant shortcomings. First, they often do not result in complete ablation of the whole Barrett's segment [15-19]. Second, studies have shown that oncogenetic alterations, as present in BE prior to ablation, can still be found in areas of residual $\mathrm{BE}$ and these may be associated with recurrence of dysplasia [20]. Third, foci of intestinal metaplasia (IM) may be hidden underneath the neosquamous mucosa after treatment (a.k.a., 'buried Barrett's') and some fear that these areas may progress to cancer without being detected endoscopically due to their 'hidden' nature [21, 22]. Lastly, PDT and APC are associated with complications of which esophageal stenosis is the most relevant [15-19]. Stepwise circumferential and focal radiofrequency ablation (RFA) combined with ER for focal lesions is a relatively new endoscopic treatment modality for BE [23-25] (fig. 2). Recent studies suggest that this ablation technique is highly effective in removing Barrett's mucosa and associated dysplasia without the aforementioned drawbacks of other ablation techniques [26-31]. This review will focus on indications for ER and the use of RFA in the management of patients with early esophageal neoplasia. 

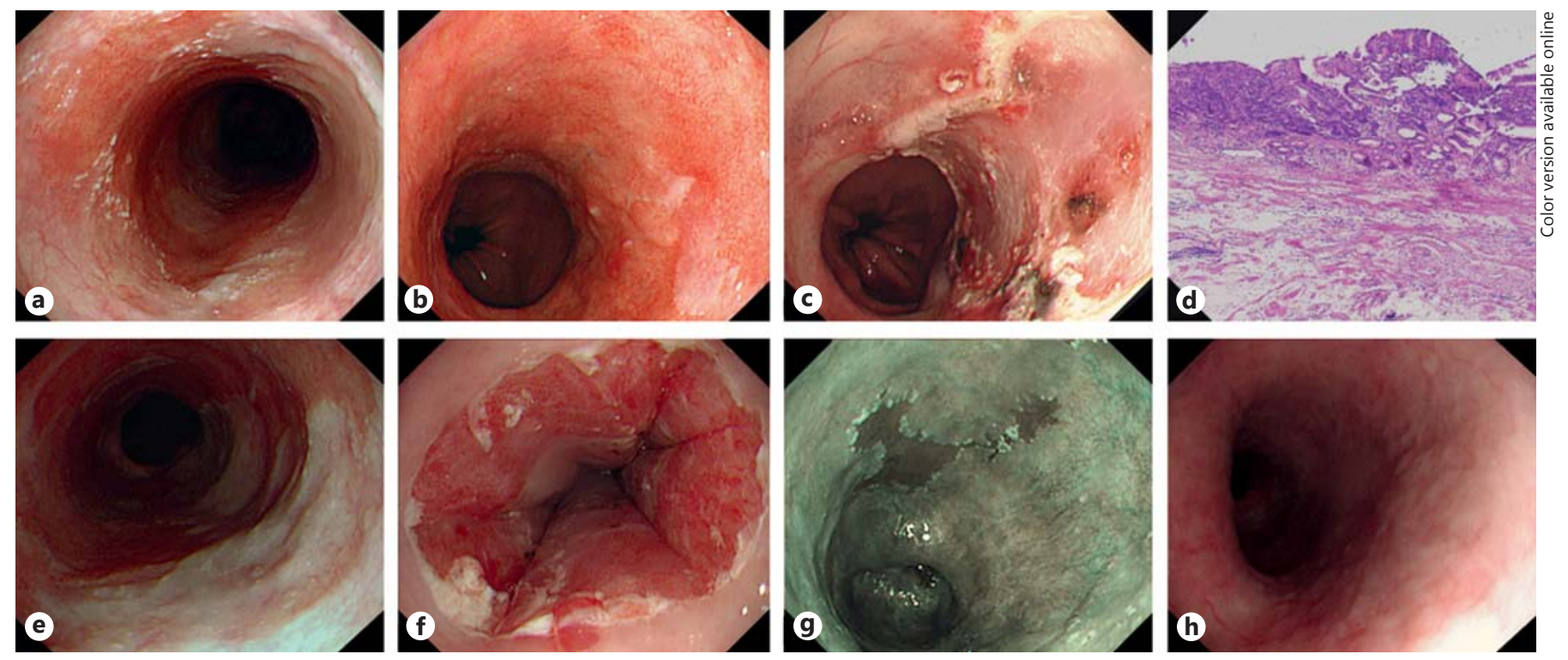

Fig. 2. Endoscopic and histological images of a C6M10 BE with early cancer treated with a combination of ER and RFA. a Antegrade view on a C6M10 BE. b A lesion suspicious for early cancer at the 2-4 o'clock position. c View on the resection wound after ER of the lesion in 2 pieces. $\mathbf{d}$ Histopathological evaluation of the specimens showed a radically resected adenocarcinoma infiltrating in the muscularis mucosae (T1m3). e Same area 6 weeks after the ER.

\section{Endoscopic Resection}

\section{ER Techniques}

In the esophagus ER is mostly performed using capbased techniques. Inoue et al. [9] first described a capbased ER technique, using a transparent distal attachment cap that is placed on the tip of an endoscope. The marked target area is lifted from the deeper esophageal wall layers by submucosal fluid injection, and then a crescent shaped snare is prelooped in the distal rim of the cap. The target lesion is then sucked into the cap, and by closing the prelooped snare, the mucosa is captured and can be resected using electrocautery. This is called the lift, suck and cut technique. ER using the ER cap technique allows for en bloc resection of lesions with a maximum diameter up to $2 \mathrm{~cm}$ [32]. A drawback of the ER cap technique is that it is a technically demanding and time consuming procedure, especially when used for piecemeal resections. Prelooping the snare in the distal rim of the cap can be challenging, and for piecemeal resections, submucosal lifting needs to be repeated for every resection.

For the ER cap technique, a number of different attachment caps are available that fit on most standard and therapeutic endoscopes. The choice ranges from hard
The wound has healed completely with scarring. $\mathbf{f}$ Ablation effect after primary circumferential ablation. $\mathbf{g}$ Residual islands of Barrett's mucosa remaining 6 weeks after prior circumferential ablation with narrow band imaging. $\mathbf{h}$ After additional focal ablation, complete removal of the whole Barrett's segment was reached. Published with permission of www.endosurgery.eu.

caps, either straight or oblique shaped, with an outer diameter of 12.8-16.1 mm to flexible oblique caps with an outer diameter of $18 \mathrm{~mm}$. The oblique caps are best suited for lesions that are located tangentially to the endoscope (such as in the esophagus), whereas straight caps can be used for lesions that are approached en face. The large caliber flexible cap results in larger and deeper resections, which increases the chance of resecting a lesion en bloc. For piecemeal resections, however, using the large caliber cap may increase the risk of complications, such as perforation. The use of standard hard caps may, therefore, be advisable for piecemeal resections. To capture and resect the mucosa, single use crescent shaped snares with a small tip are used. Because the snares easily loose their shape, usually a new snare is needed for every resection.

The ligate and cut technique, or multiband mucosectomy (MBM) technique, is an easier alternative to the lift, suck and cut technique. The MBM technique is based on the variceal band ligator. A distal attachment cap, holding multiple rubber bands, is attached to the tip of the endoscope. The target lesion is sucked into the cap, and by releasing a rubber band, the mucosa is captured. This pseudo-polyp can then be resected with a snare. An advantage 
of the MBM technique over the lift, suck and cut technique is that no submucosal lifting is required, since the rubber band is not strong enough to hold in the deeper esophageal wall layers.

A prospective registration of $243 \mathrm{MBM}$ procedures in patients with $\mathrm{BE}$ demonstrated that the technique is safe and effective. Acute complications occurring during the procedure, all endoscopically managed bleedings, were observed in 3\% of procedures. No perforations occurred. Endoscopic complete resection was achieved in $91 \%$ of focal lesions [33].

In a case-control study, $80 \mathrm{MBM}$ procedures were compared with 86 ER-cap procedures. The study showed that MBM was safe and effective for widespread ER in BE. MBM appeared to be quicker than ER cap, but the specimens removed with MBM were significantly smaller than with the ER cap technique [34].

Following this case-control study, a multicenter randomized controlled trial was initiated to compare the ER cap technique and MBM for piecemeal resection of early neoplasia in BE [32]. The trial included 84 patients (42 assigned to MBM and 42 to ER cap) and found that procedure times and costs were significantly less with MBM versus ER cap ( 34 vs. $50 \mathrm{~min}$ and 240 vs. 322 euro, respectively). MBM resulted in smaller specimens than the ER cap technique (18 vs. $20 \mathrm{~mm}$ ). There were no significant differences in maximum specimen thickness or the amount of submucosa resected. There were 3 perforations in the ER cap group and 1 perforation in the MBM group. MBM appears to be safe and fast for widespread ER in BE. Time and costs appear to be saved compared with ER cap, since submucosal lifting is not required and a single snare can be used for all resections. MBM does not appear to be associated with more complications than ER cap, despite lack of submucosal lifting. MBM results in significantly smaller sized resections, but the clinical relevance of this finding may be questioned, since there was no significant difference in the depth of resection between the 2 .

\section{Endoscopic Submucosal Dissection [35, 36]}

Endoscopic submucosal dissection (ESD) is a technique that overcomes the problem of piecemeal ER for larger neoplastic lesions and allows for a better targeted resection of a lesion. The concept of ESD is to incise the mucosa around a lesion, regardless how large, and then remove the mucosa by submucosal dissection using an electrosurgical knife instead of a snare. After careful delineation of a lesion, coagulation markings can be placed around the lesion using the tip of an electrosurgical knife, about $5 \mathrm{~mm}$ outside the margins of the lesion. The marked incision line and the mucosa within the markings are lifted by submucosal fluid injection. With an electrosurgical knife, the incision line can then be incised circumferentially around the lesion, while constantly repeating submucosal lifting to ensure a safe submucosal fluid cushion. When the incision around the lesion has been completed, the submucosa underneath the lesion can be dissected completely to remove the diseased part of the mucosa in one piece. However, ESD is a complex intervention requiring lots of experience of the endoscopist. For early neoplasia in $\mathrm{BE}$, additional ablation of the remainder of the Barrett's is performed in the majority of patients. The need for en bloc resection may therefore be of less importance and a combination of cap-based piecemeal ER followed by ablation can be considered an easier, safe and effective alternative in patients with widespread lesions. Indications for ESD in BE may be larger lesions $(>2 \mathrm{~cm}$ ) with a high likelihood for submucosal invasion, and/or a bulky intraluminal component that would otherwise fill the cap during suctioning and will result in positive vertical resection margins. These lesions are, however, in general $<10 \%$ of cases of early esophageal neoplasia.

\section{Indications for ER}

\section{Early Neoplasia Arising in BE}

ER for early neoplasia in BE has been proven safe and effective for lesions limited to the mucosa (m1$\mathrm{m} 3$ ). The risk on lymph node metastasis in these patients is $<2 \%$, which is lower than the 30 -day mortality risk after surgical esophagectomy. Strict indications for ER in a BE are solitary lesions types 0-I, 0-IIa, 0-IIb or 0 -IIc, with a maximum diameter of $2 \mathrm{~cm}$. If histopathological evaluation shows that a lesion was radically resected, limited to the mucosa (high grade dysplasia, $\mathrm{m} 1$, $\mathrm{m} 2, \mathrm{~m} 3$ ) and well to moderately differentiated, and if there were no signs of lymphatic or vascular infiltration, it can be assumed that the patient was curatively treated [1-4]. In these patients, additional treatment to eradicate the residual Barrett's epithelium to prevent metachronous lesions is justified. Relative indications for ER of early Barrett neoplasia are infiltration in the superficial submucosa (T1sm1, $<500 \mu \mathrm{m})$, poorly differentiated cancer (G3) and lesions with a diameter $>2 \mathrm{~cm}$. In case of infiltration beyond the superficial submucosa ( $>\mathrm{sm} 1)$, lymphatic or vascular infiltration or undifferentiated cancer (G4), patients should not be 
treated endoscopically, but with alternative treatment modalities such as surgery, chemo- and/or radiotherapy [10-13].

\section{Early Squamous Neoplasia in the Esophagus}

Compared to Barrett's neoplasia, esophageal squamous neoplasia invades the muscularis mucosae and submucosa at a particularly early stage, lymphatic invasion then occurs quickly, and distant metastases are seen in nearly $30 \%$ of patients [37]. Indications to perform ER of esophageal squamous cell carcinoma are flat type lesions (types 0 -IIa, 0 -IIb, 0 -IIc) that are mostly limited to the mucosa. Protruding (type $0-\mathrm{I}$ ) and ulcerated lesions (type 0-III) almost always invade the submucosa and should not be resected endoscopically [38]. Lesions that are histologically confined to the epithelium and lamina propria $(\mathrm{m} 1, \mathrm{~m} 2)$ have a very low rate of local lymph node metastases $(<5 \%)$ and are considered amenable for endoscopic treatment [39]. Lesions invading into the muscularis mucosa (m3) or superficial submucosa ( $\mathrm{sm} 1$ ), however, have an increased risk of lymph node metastases of approximately $10 \%$ [39]. These lesions are, therefore, only relative indications for endoscopic treatment, for example, in patients who carry an increased risk for severe complications of esophagectomy.

\section{Radiofrequency Ablation}

\section{RFA Technique}

In most patients, RFA of BE starts with a circumferential ablation procedure. A standard procedure consists of sizing the esophageal inner diameter (EID) at multiple levels using a sizing catheter. Then an ablation balloon catheter with the appropriate diameter $(18-31 \mathrm{~mm})$ is selected and the entire length of the $\mathrm{BE}$ is ablated. Patients undergo follow-up endoscopy 12 weeks after the first circumferential ablation treatment and additional circumferential RFA is performed if there is residual circumferential Barrett's measuring $>2 \mathrm{~cm}$, multiple islands or tongues of columnar epithelium. Otherwise, focal ablation of residual Barrett's mucosa and the gastroesophageal junction is performed using the Barrx ${ }^{90}$ device. The Barrx ${ }^{90}$ device consists of an electrode array of $20 \mathrm{~mm}$ mounted on an articulated platform. The Barrx ${ }^{360}$ device and the Barrx ${ }^{90}$ device are used in combination with the Barrx Flex system (GI solutions Covidien/Medtronic, Sunnyvale, Calif., USA). The electrodes are designed to deliver uniform bipolar radiofrequency energy to the tissue resulting in a controlled ablation depth of $500-1,000 \mu \mathrm{m}$.

Endoscopic Management of Early

Esophageal Cancer
Efficacy of RFA Treatment for Dysplastic BE

The efficacy of RFA treatment for BE has been studied extensively. Studies to date show complete eradication of IM (CE-IM) rates ranging from 54 to $100 \%$ and complete eradication of dysplasia (CE-D) rates ranging from 80 to $100 \%$ for dysplastic and non-dysplastic BE patients [2631, 40-43]. Recently, several groups have published longterm follow-up results. A high proportion of patients achieving CE-IM and CE-D remains free of recurrence with sustained CE-IM rates reported to be between 77 and $92 \%$ and sustained CE-D ranging from 94 to $98 \%$ after a median follow-up duration varying from 24 to 61 months [44-50]. It can be concluded that RFA is effective in eradicating $\mathrm{BE}$ with different grades of dysplasia.

\section{Adverse Events after RFA}

Adverse events reported with RFA include esophageal strictures, upper gastrointestinal hemorrhage and chest pain $[29,47]$. Stricture rates of $0-56 \%$ have been described with other endoscopic ablation techniques [15-19]. Overall, studies of RFA for BE have shown lower rates of stricturing (0-6\%) [26-31, 47]. The stricturing seen with RFA has generally been associated with either prior ER or a narrow esophagus at baseline due to underlying reflux disease.

In a sham-controlled study of 127 patients, $6 \%$ of the RFA cohort experienced a stricture, but all resolved with a mean of 2.6 dilations [29]. There were no perforations or deaths.

In a community-based registry of 429 patients, 9 strictures occurred following 788 procedures ( $1 \%$ of cases and $2 \%$ of patients) [41]. All the strictures resolved after a median of 3 dilations. There were no cases of bleeding requiring repeat endoscopy, perforation or death.

Performing ER prior to RFA may increase the risk of complications. In a study of 65 patients, there were no complications in the 18 patients who had not previously undergone ER [42]. In the 47 patients who had undergone ER prior to circumferential RFA, mucosal lacerations were observed in patients who underwent RFA with a catheter that exceeded the smallest measured EID and in patients whose ER involved more than one-third of the esophageal circumference and was $>2.5 \mathrm{~cm}$ in length. Five cases of esophageal stenosis after RFA occurred, all in patients whose ER involved $>50 \%$ of the esophageal circumference and was longer than $2 \mathrm{~cm}$ in length.

Based on these observations, it is advisable to choose the size of the ablation catheters carefully in cases of prior ER and to limit the extent of prior ER to $2 \mathrm{~cm}$ in length and $50 \%$ of the circumference if possible. 


\section{Future Perspectives in Endoscopic Management for Early Esophageal Neoplasia}

Over the last decades, ER of early gastroesophageal neoplasia in selected patients has been proven a safe and effective alternative to surgical resection. Adequate endoscopic work-up to identify patients that are eligible for endoscopic treatment is of the utmost importance, to select patients with a minimal risk of lymphatic involvement that can be cured by local endoscopic treatment. ER plays a pivotal role in this patient selection since it provides a large tissue specimen for accurate histological evaluation of risk factors for lymphatic involvement. To ensure optimal endoscopic work-up, histological evaluation and patient management, patients should be referred to centers with multidisciplinary expertise in this field.

A number of different ER techniques are available. Developments such as the MBM device make widespread ER easier, faster and possibly safer. Other developments, such as ESD, widen the indication for ER by allowing en bloc resection of lesions with a diameter $>2 \mathrm{~cm}$. A number of promising new techniques are being developed all aimed at making ER easier to perform, safer, and to allow for en bloc resection of larger lesions.

In cases of early neoplasia arising in BE, RFA has been proven to be highly effective in eradicating IM and its associated dysplasia, it has a low complication rate, preserves the esophageal functional integrity and is relatively easy to apply. Recent developments in endoscopic techniques have significantly improved patient care over the past years. Different ablation regimens have been studied leading to simplified ablation regimens. Circumferential ablation is cheaper and faster, but equally safe and effective, when the cleaning phase between ablations is omitted.

Recently, the Barrx ${ }^{360}$ Express RFA balloon catheter (Express 360) has been developed. The Express 360 is a circumferential balloon catheter, which contains a $4 \mathrm{~cm}$ long bipolar electrode that is wrapped around a balloon and that features the ability to self-adjust to the inner esophageal lumen. Therefore, the Express 360 may adjust for differences in EID over the length of the ablation zone. Furthermore, circumferential ablation using the Express 360 may result in shorter procedure duration and decreased patient discomfort since less introductions of the endoscope and catheters are necessary. The Express 360 is currently being studied in a randomized trial.

Different ablation regimens for focal ablation have been studied as well. However, there is still controversy about the ideal energy settings for focal ablation. In Europe, the focal device has been mainly used at $15 \mathrm{~J} / \mathrm{cm}^{2}$, both for the standard and the simplified regimen. Lowering the energy density to $12 \mathrm{~J} / \mathrm{cm}^{2}$ (in accordance to the US standard protocol) when using the simplified triple application may reduce the risk of fibrosis and stenosis. A randomized clinical trial comparing the standard regimen $\left(2 \times 15 \mathrm{~J} / \mathrm{cm}^{2}-\right.$ clean $\left.-15 \mathrm{~J} / \mathrm{cm}^{2}\right)$ to the simple triple regimen $\left(3 \times 12 \mathrm{~J} / \mathrm{cm}^{2}-\right.$ no clean $)$ is currently being conducted.

\section{Disclosure Statement}

Jacques Bergman received financial support for research from Covidien/Medtronic, Olympus Endoscopy, Cook Medical, Boston Scientific, Erbe Medical, C2Therapeutic, and Ninepoint Medical. All other authors disclosed no financial relationships relevant to this publication.

\section{References}

1 Ell C, May A, Gossner L, et al: Endoscopic mucosal resection of early cancer and highgrade dysplasia in Barrett's esophagus. Gastroenterology 2000;118:670-677.

-2 May A, Gossner L, Pech O, et al: Local endoscopic therapy for intraepithelial high-grade neoplasia and early adenocarcinoma in Barrett's oesophagus: acute-phase and intermediate results of a new treatment approach. Eur J Gastroenterol Hepatol 2002;14:10851091.

-3 Peters FP, Kara MA, Rosmolen WD, et al: Endoscopic treatment of high-grade dysplasia and early stage cancer in Barrett's esophagus. Gastrointest Endosc 2005;61: 506-514.
4 Pech O, Behrens A, May A, et al: Long-term results and risk factor analysis for recurrence after curative endoscopic therapy in 349 patients with high-grade intraepithelial neoplasia and mucosal adenocarcinoma in Barrett's oesophagus. Gut 2008;57:1200-1206.

5 Ono H, Kondo H, Gotoda T, et al: Endoscopic mucosal resection for treatment of early gastric cancer. Gut 2001;48:225-229.

-6 Peters FP, Brakenhoff KP, Curvers WL, et al: Histologic evaluation of resection specimens obtained at 293 endoscopic resections in Barrett's esophagus. Gastrointest Endosc 2008; 67:604-609.

7 Tanabe S, Koizumi W, Kokutou M, et al: Usefulness of endoscopic aspiration mucosecto- my as compared with strip biopsy for the treatment of gastric mucosal cancer. Gastrointest Endosc 1999;50:819-822.

$\checkmark 8$ Inoue $\mathrm{H}$, Takeshita $\mathrm{K}$, Hori $\mathrm{H}$, et al: Endoscopic mucosal resection with a cap-fitted panendoscope for esophagus, stomach, and colon mucosal lesions. Gastrointest Endosc 1993;39:58-62.

-9 Inoue H, Endo M, Takeshita K, et al: A new simplified technique of endoscopic esophageal mucosal resection using a cap-fitted panendoscope (EMRC). Surg Endosc 1992;6:264-265.

10 Nigro JJ, Hagen JA, DeMeester TR, et al: Occult esophageal adenocarcinoma: extent of disease and implications for effective therapy. Ann Surg 1999;230:433-438; discussion 438-440. 
11 Rice TW, Blackstone EH, Goldblum JR, et al: Superficial adenocarcinoma of the esophagus. J Thorac Cardiovasc Surg 2001;122:10771090.

12 Araki K, Ohno S, Egashira A, et al: Pathologic features of superficial esophageal squamous cell carcinoma with lymph node and distal metastasis. Cancer 2002;94:570-575.

13 Buskens CJ, Westerterp M, Lagarde SM, et al: Prediction of appropriateness of local endoscopic treatment for high-grade dysplasia and early adenocarcinoma by EUS and histopathologic features. Gastrointest Endosc 2004;60: 703-710.

14 May A, Gossner L, Pech O, et al: Local endoscopic therapy for intraepithelial high-grade neoplasia and early adenocarcinoma in Barrett's oesophagus: acute-phase and intermediate results of a new treatment approach. Eur J Gastroenterol Hepatol 2002;14:1085-1091.

${ }_{15}$ Overholt BF, Panjehpour M, Halberg DL: Photodynamic therapy for Barrett's esophagus with dysplasia and/or early stage carcinoma: long-term results. Gastrointest Endosc 2003;58:183-188.

16 Peters F, Kara M, Rosmolen W, et al: Poor results of 5-aminolevulinic acid-photodynamic therapy for residual high-grade dysplasia and early cancer in Barrett esophagus after endoscopic resection. Endoscopy 2005;37:418-424.

$\checkmark 17$ Hage M, Siersema PD, van Dekken H, et al: 5-Aminolevulinic acid photodynamic therapy versus argon plasma coagulation for ablation of Barrett's oesophagus: a randomised trial. Gut 2004;53:785-790.

-18 Schulz H, Miehlke S, Antos D, et al: Ablation of Barrett's epithelium by endoscopic argon plasma coagulation in combination with high-dose omeprazole. Gastrointest Endosc 2000;51:659-663.

19 Van Laethem JL, Jagodzinski R, Peny MO, et al: Argon plasma coagulation in the treatment of Barrett's high-grade dysplasia and in situ adenocarcinoma. Endoscopy 2001;33:257-261.

20 Krishnadath KK, Wang KK, Taniguchi K, et al: Persistent genetic abnormalities in Barrett's esophagus after photodynamic therapy. Gastroenterology 2000;19:624-630.

-21 Van Laethem JL, Peny MO, Salmon I, et al: Intramucosal adenocarcinoma arising under squamous re-epithelialisation of Barrett's oesophagus. Gut 2000;46:574-577.

22 Mino-Kenudson M, Ban S, Ohana M, et al: Buried dysplasia and early adenocarcinoma arising in Barrett esophagus after porfimerphotodynamic therapy. Am J Surg Pathol 2007;31:403-409.

23 Ganz RA, Utley DS, Stern RA, et al: Complete ablation of esophageal epithelium with a balloon-based bipolar electrode: a phased evaluation in the porcine and in the human esophagus. Gastrointest Endosc 2004;60:1002-1010.

-24 Dunkin BJ, Martinez J, Bejarano PA, et al: Thin-layer ablation of human esophageal epithelium using a bipolar radiofrequency balloon device. Surg Endosc 2006;20:125-130.
25 Smith CD, Bejarano PA, Melvin WS, et al: Endoscopic ablation of intestinal metaplasia containing high-grade dysplasia in esophagectomy patients using a balloon-based ablation system. Surg Endosc 2007;21:560-569.

26 Sharma VK, Wang KK, Overholt BF, et al: Balloon-based, circumferential, endoscopic radiofrequency ablation of Barrett's esophagus: 1-year follow-up of 100 patients. Gastrointest Endosc 2007;65:185-195.

27 Fleischer DE, Overholt BF, Sharma VK, et al: Endoscopic ablation of Barrett's esophagus: a multicenter study with 2.5-year follow-up. Gastrointest Endosc 2008;68:867-876.

28 Sharma VK, Jae Kim H, Das A, et al: Circumferential and focal ablation of Barrett's esophagus containing dysplasia. Am J Gastroenterol 2009;104:310-317.

29 Shaheen NJ, Sharma P, Overholt BF, et al: Radiofrequency ablation in Barrett's esophagus with dysplasia. N Engl J Med 2009;360:22772288.

30 Gondrie JJ, Pouw RE, Sondermeijer CM, et al: Stepwise circumferential and focal ablation of Barrett's esophagus with high-grade dysplasia: results of the first prospective series of 11 patients. Endoscopy 2008;40:359-369.

31 Gondrie JJ, Pouw RE, Sondermeijer CM, et al: Effective treatment of early Barrett's neoplasia with stepwise circumferential and focal ablation using the HALO system. Endoscopy 2008;40:370-379.

32 Pouw RE, van Vilsteren FG, Peters FP, et al: Randomized trial on endoscopic resectioncap versus multiband mucosectomy for piecemeal endoscopic resection of early Barrett's neoplasia. Gastrointest Endosc 2011;74:3543.

33 Alvarez Herrero L, Pouw RE, van Vilsteren FG, et al: Safety and efficacy of multiband mucosectomy in 1060 resections in Barrett's esophagus. Endoscopy 2011;43:177-183.

34 Peters FP, Kara MA, Curvers WL, et al: Multiband mucosectomy for endoscopic resection of Barrett's esophagus: feasibility study with matched historical controls. Eur J Gastroenterol Hepatol 2007;19:311-315.

35 Miyamoto S, Muto M, Hamamoto Y, et al: A new technique for endoscopic mucosal resection with an insulated-tip electrosurgical knife improves the completeness of resection of intramucosal gastric neoplasms. Gastrointest Endosc 2002;55:576-581.

36 Chevaux JB, Piessevaux H, Jouret-Mourin A, et al: Endoscopic submucosal dissection for superficial Barrett's esophagus adenocarcinoma: clinical outcomes in a large series of European patients. Endoscopy 2015;47:103112.

37 Araki K, Ohno S, Egashira, et al: Pathologic features of superficial esophageal squamous cell carcinoma with lymph node and distal metastasis. Cancer 2002;94:570-575.
38 The Paris endoscopic classification of superficial neoplastic lesions: esophagus, stomach, and colon: November 30 to December 1, 2002. Gastrointest Endosc 2003;58:S3-S43.

-39 Pech O, Gossner L, May A, et al: Endoscopic resection of superficial esophageal squamouscell carcinomas: western experience. Am J Gastroenterol 2004;99:1226-1232.

40 Ganz RA, Overholt BF, Sharma VK, et al: Circumferential ablation of Barrett's esophagus that contains high-grade dysplasia: a U.S. multicenter registry. Gastrointest Endosc 2008;68:35-40.

41 Lyday WD, Corbett FS, Kuperman DA, et al: Radiofrequency ablation of Barrett's esophagus: outcomes of 429 patients from a multicenter community practice registry. Endoscopy 2010;42:272-278.

42 Pouw RE, Wirths K, Eisendrath P, et al: Efficacy of radiofrequency ablation combined with endoscopic resection for Barrett's esophagus with early neoplasia. Clin Gastroenterol Hepatol 2010;8:23-29.

43 Van Vilsteren FG, Pouw RE, Seewald S, et al: Stepwise radical endoscopic resection versus radiofrequency ablation for Barrett's oesophagus with high-grade dysplasia or early cancer: a multicentre randomised trial. Gut 2011; 60:765-773.

44 Gupta M, Iyer PG, Lutzke L, et al: Recurrence of esophageal intestinal metaplasia after endoscopic mucosal resection and radiofrequency ablation of Barrett's esophagus: results from a US multicenter consortium. Gastroenterology 2013;145:79-86.e1.

45 Haidry RJ, Butt MA, Dunn JM, et al: Improvement over time in outcomes for patients undergoing endoscopic therapy for Barrett's oesophagus-related neoplasia: 6-year experience from the first 500 patients treated in the UK patient registry. Gut 2015; 64:1192-1199.

46 Pasricha S, Bulsiewicz WJ, Hathorn KE, et al: Durability and predictors of successful radiofrequency ablation for Barrett's esophagus. Clin Gastroenterol Hepatol 2014;12:1840-1847.e1.

47 Phoa KN, Pouw RE, Bisschops R, et al: Multimodality endoscopic eradication for neoplastic Barrett oesophagus: results of an European multicentre study (EURO-II). Gut 2016;65: 555-562.

48 Fleischer DE, Overholt BF, Sharma VK, et al: Endoscopic radiofrequency ablation for Barrett's esophagus: 5-year outcomes from a prospective multicenter trial. Endoscopy 2010; 42:781-789.

49 Shaheen NJ, Overholt BF, Sampliner RE, et al: Durability of radiofrequency ablation in Barrett's esophagus with dysplasia. Gastroenterology 2011;141:460-468.

50 Phoa KN, Pouw RE, van Vilsteren FG, et al: Remission of Barrett's esophagus with early neoplasia 5 years after radiofrequency ablation with endoscopic resection: a Netherlands cohort study. Gastroenterology 2013;145:96104.
Endoscopic Management of Early Esophageal Cancer
Dig Dis 2016;34:469-475 DOI: $10.1159 / 000445221$ 